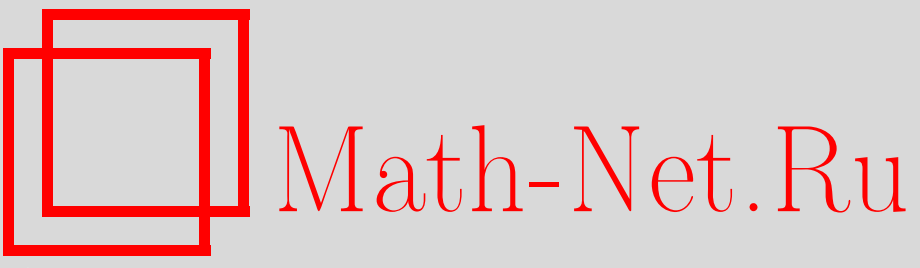

V. P. Maksimov, The structure of the Cauchy operator to a linear continuous-discrete functional differential system with aftereffect and some properties of its components, Vestn. Udmurtsk. Univ. Mat. Mekh. Komp. Nauki, 2019, Volume 29, Issue 1, 40-51

DOI: https://doi.org/10.20537/vm190104

Use of the all-Russian mathematical portal Math-Net.Ru implies that you have read and agreed to these terms of use

http://www.mathnet.ru/eng/agreement

Download details:

IP : 18.209 .158 .208

April 26, 2023, 12:19:25 
MSC2010: 34K10, 34K30, 34K35, $91 \mathrm{~B} 74$

\author{
(C) V.P. Maksimov
}

\title{
THE STRUCTURE OF THE CAUCHY OPERATOR TO A LINEAR CONTINUOUS-DISCRETE FUNCTIONAL DIFFERENTIAL SYSTEM WITH AFTEREFFECT AND SOME PROPERTIES OF ITS COMPONENTS
}

In this paper, a class of linear functional differential systems with aftereffect, continuous and discrete times, and impulses (impulse hybrid systems) is considered. The focus of attention is on the structure of the Cauchy operator to the hybrid system under consideration and the representation of their components. Those allow one to give the representation of all trajectories of the hybrid system and to formulate conditions of the solvability for control problems in various classes of controls, to obtain estimates of the attainability sets under constrained control, and to study general linear boundary value problems for the solvability. A detailed description of all components to the Cauchy operator is given and their properties are studied. For the components with continuous time, some conditions of the continuity with respect to the second argument are obtained which is related to deciding on a class of controls. The main results are based on constructions of the Cauchy matrices to systems with continuous time and difference systems.

Keywords: linear systems with delay, functional differential systems with continuous and discrete times, representation of solutions, Cauchy operator.

DOI: $10.20537 / \mathrm{vm} 190104$

\section{Introduction}

The class of systems under consideration covers many systems that arise in mathematical modelling of economic dynamics processes and includes various kinds of models with aftereffect such as integro-differential systems, systems with distributed and lumped delay and allows one to take into account the response of the system to external impulse disturbances.

The system under consideration includes two types of variables simultaneously, namely, the state variables depending on the continuous time, $t \in[0, T]$, and the variables with dependence on the discrete time, $t \in\left\{0, t_{1}, \ldots, t_{N}, T\right\}$. In such a situation, the term "hybrid systems" is of frequent use. As this term has many different senses, we follow the author of $[1,2]$ and apply the more definite term "continuous-discrete systems". It should be noted that, in the above works, a detailed motivation for the study of certain classes of continuous-discrete systems as well as some examples of the urgent applied problems such as stabilization, observability, and controllability problems are presented. For further results on the problems mentioned we refer the reader to [24-26] and the references therein.

First we describe the class of continuous-discrete systems in detail and define the operators and the spaces where they act. The focus of attention is on the representation of the general solution. We derive the main relationships for the fundamental matrix and the Cauchy operator, investigate their structure and describe an approach to studying the properties of the separate components.

The results obtained here form the basis for the study of control problems and boundary value problems for continuous-discrete systems with aftereffect and develop the previous results presented in $[10,15,17-19,21,22]$. In the sequel, we follow the notation and the definitions of those works.

\section{§1. A class of continuous-discrete functional-differential equations with aftereffect}

Let us introduce the Banach spaces where the operators and the equations are considered and describe the main subject. 
Fix a segment $[0, T] \subset R$. We denote by $L^{n}=L^{n}[0, T]$ the space of summable functions $v:[0, T] \rightarrow R^{n}$ with the norm $\|v\|_{L^{n}}=\int_{0}^{T}|v(s)|_{n} d s$, where $|\cdot|_{n}$ (or $|\cdot|$ for short if the dimension value is clear) stands for the norm in $R^{n}$. The symbol $V$ we use for the integrating operator: $(V v)(t)=\int_{0}^{t} v(s) d s$

Next we fix the set $\left\{\tau_{1}, \ldots, \tau_{m}\right\}, 0<\tau_{1}<\ldots<\tau_{m}<T$, and define the space $D S^{n}(m)=$ $=D S^{n}\left[0, \tau_{1}, \ldots, \tau_{m}, T\right]$ (see $[4,7]$ ) as the space of piecewise absolutely continuous functions $x:[0, T] \rightarrow R^{n}$ representable in the form

$$
x(t)=\int_{0}^{t} v(s) d s+x(0)+\sum_{k=1}^{m} \chi_{\left[\tau_{k}, T\right]}(t) \Delta x\left(\tau_{k}\right),
$$

where $v \in L^{n}, \Delta x\left(\tau_{k}\right)=x\left(\tau_{k}\right)-x\left(\tau_{k}-0\right), \chi_{\left[\tau_{k}, T\right]}(t)$ is the characteristic function of $\left[\tau_{k}, T\right]$ : $\chi_{\left[\tau_{k}, T\right]}(t)=1$, if $t \in\left[\tau_{k}, T\right]$ and $\chi_{\left[\tau_{k}, T\right]}(t)=0, t \notin\left[\tau_{k}, T\right]$. Thus the elements of $D S^{n}(m)$ are absolutely continuous on each of $\left[0, \tau_{1}\right),\left[\tau_{1}, \tau_{2}\right), \ldots,\left[\tau_{m}, T\right]$ and continuous from the right at the points $\tau_{1}, \ldots, \tau_{m}$. Under the norm

$$
\|x\|_{D S^{n}(m)}=\|\dot{x}\|_{L^{n}}+|x(0)|_{n}+\sum_{k=1}^{m}\left|\Delta x\left(t_{k}\right)\right|_{n}
$$

the space $D S^{n}(m)$ is Banach.

Let us recall [6] that, for any linear bounded operator $\mathcal{T}: D S^{n}(m) \rightarrow L^{n}$, the operator $Q: L^{n} \rightarrow L^{n}$ defined by $Q=\mathcal{T} V$ is called the principal part of $\mathcal{T}$.

The space $D S^{n}(m)$ was introduced in the theory of impulse systems by A. Anokhin [4] and came into use as the basis for a new approach to studying wide classes of problems. Here we restrict ourselves to some remarks only and refer the reader to [6] for more details. The theory of differential equations with discontinuous solutions was initiated by J. Kurzweil in [11], where the "generalized ordinary differential equations" are considered. Nowadays this theory is highly developed, see, for instance, $[5,27]$. Within the framework of this theory, the impulse equations are considered in the class of functions of bounded variation, and the solutions are defined as functions that satisfy an integral equation with either the Lebesgue-Stieltjes integral or the Perron-Stieltjes one. The integral equations in the space of functions of bounded variation are studied in detail in the monograph [28]. Let us recall that any function of bounded variation has the representation as the sum of an absolutely continuous function, a jump function, and a singular one. Thus, dealing with functions from $D S^{n}(m)$, we fix a finite number of jump points and omit the singular component that does not arise in many applied problems, say, in economic dynamics [9,23].

Next we fix the set $\left\{t_{0}, t_{1}, \ldots, t_{\mu}\right\}, 0=t_{0}<t_{1}<\ldots<t_{\mu}=T$.

Let $F D^{\nu}(\mu)=F D^{\nu}\left\{t_{0}, t_{1}, \ldots, t_{\mu}\right\}$ be the space of functions $z: J \rightarrow R^{\nu}$ under the norm

$$
\|z\|_{F D^{\nu}(\mu)}=\sum_{i=0}^{\mu}\left|z\left(t_{i}\right)\right|_{\nu} .
$$

We consider the system

$$
\begin{aligned}
\dot{x} & =\mathcal{T}_{11} x+\mathcal{T}_{12} z+f, \\
z & =\mathcal{T}_{21} x+\mathcal{T}_{22} z+g,
\end{aligned}
$$

where the linear operators $\mathcal{T}_{i j}, i, j=1,2$, are defined as follows below.

$$
\begin{gathered}
\mathcal{T}_{11}: D S^{n}(m) \rightarrow L^{n} \\
\left(\mathcal{T}_{11} x\right)(t)=\int_{0}^{t} K^{1}(t, s) \dot{x}(s) d s+A_{0}^{1}(t) x(0)+\sum_{k=1}^{m} A_{k}^{1}(t) \chi_{\left[\tau_{k}, T\right]}(t) \Delta x\left(\tau_{k}\right), \quad t \in[0, T] .
\end{gathered}
$$


Here the kernel $K(t, s)$ is assumed to satisfy the condition $\mathcal{K}$ [18]: the elements $k_{i j}^{1}(t, s)$ are Lebesgue measurable on the set $0 \leqslant s \leqslant t \leqslant T$ and have a common majorant $\kappa(\cdot)$ summable on $[0, T]$ such that $\left|k_{i j}^{1}(t, s)\right| \leqslant \kappa(t), i, j=1, \ldots, n ;(n \times n)$-matrices $A_{0}^{1}, \ldots, A_{m}^{1}$ have elements summable on $[0, T]$.

$$
\mathcal{T}_{12}: F D^{\nu}(\mu) \rightarrow L^{n} ; \quad\left(\mathcal{T}_{12} z\right)(t)=\sum_{\left\{j: t_{j}<t\right\}} B_{j}^{1}(t) z\left(t_{j}\right), \quad t \in[0, T]
$$

where elements of matrices $B_{j}^{1}, j=0, \ldots, \mu$, are summable on $[0, T]$. As usual, we put $\sum_{i=k}^{l} F_{i}=0$ for any $F_{i}$, if $l<k$.

$$
\begin{gathered}
\mathcal{T}_{21}: D S^{n}(m) \rightarrow F D^{\nu}(\mu) \\
\left(\mathcal{T}_{21} x\right)\left(t_{i}\right)=\int_{0}^{t_{i}} K_{i}^{2}(s) \dot{x}(s) d s+A_{i 0}^{2} x(0)+\sum_{k: \tau_{k} \leqslant t_{i}} A_{i k}^{2} \Delta x\left(\tau_{k}\right), \quad i=0,1, \ldots, \mu,
\end{gathered}
$$

where elements of matrices $K_{i}^{2}$ are measurable and essentially bounded on $[0, T], A_{i k}^{2}, i=0,1, \ldots, \mu$, $k=0,1, \ldots, m$, are constant $(\nu \times n)$-matrices.

$$
\mathcal{T}_{22}: F D^{\nu}(\mu) \rightarrow F D^{\nu}(\mu) ; \quad\left(\mathcal{T}_{22} z\right)(t)=\sum_{j=0}^{i-1} B_{i j}^{2} z\left(t_{j}\right), \quad i=1, \ldots, \mu,
$$

with constant $(\nu \times \nu)$-matrices $B_{i j}^{2}$.

\section{§2. The Cauchy operator and the fundamental matrix of a continuous-discrete functional differential system with impulse impact}

In the sequel we use some results of $[7,8,12,13]$ concerning the equation

$$
\dot{x}=\mathcal{T}_{11} x+f
$$

and results of [3] concerning the equation

$$
z=\mathcal{T}_{22} z+g
$$

Recall that the homogeneous equation (2.1) $(f(t)=0, t \in[0, T])$ has the fundamental $(n \times$ $\times(n+m n))$-matrix $X(t)$ :

$$
X(t)=\Theta(t)+X_{0}(t)
$$

where

$$
\Theta(t)=\left(E_{n}, \chi_{\left[\tau_{1}, T\right]} E_{n}, \ldots, \chi_{\left[\tau_{m}, T\right]} E_{n}\right),
$$

$E_{n}$ is the identity $(n \times n)$-matrix, each column $x_{0 i}(t)$ of the $(n \times(n+m n))$-matrix $X_{0}(t)$ is the solution to the Cauchy problem

$$
\dot{x}(t)=\int_{0}^{t} K^{1}(t, s) \dot{x}(s) d s+\widetilde{a}_{i}^{1}(t), \quad x(0)=0, \quad t \in[0, T] .
$$

Here $\widetilde{a}_{i}^{1}(t)$ is the $i$ th column of $\widetilde{A}^{1}=\left(A_{0}^{1}, A_{1}^{1}, \ldots, A_{m}^{1}\right)$.

The solution to $(2.1)$ with the initial condition $x(0)=0$ has the representation

$$
x(t)=\left(C_{1} f\right)(t)=\int_{0}^{t} C_{1}(t, s) f(s) d s
$$


where $C_{1}(t, s)$ is the Cauchy matrix of the operator $d / d t-\mathcal{T}_{11}$. This matrix can be defined and constructed as the solution of the equation

$$
\frac{\partial}{\partial t} C_{1}(t, s)=\int_{s}^{t} K^{1}(t, \tau) \frac{\partial}{\partial \tau} C_{1}(\tau, s) d \tau+K^{1}(t, s), \quad 0 \leqslant s \leqslant t \leqslant T,
$$

with the condition $C_{1}(s, s)=E_{n}$, or as the solution of the integral equation

$$
C_{1}(t, s)=\int_{s}^{t} C_{1}(t, \tau) K^{1}(\tau, s) d \tau+E_{n}
$$

$C_{1}(t, s)$ can be expressed in terms of the resolvent kernel $R(t, s)$ to the kernel $K^{1}(t, s)$. Namely,

$$
C_{1}(t, s)=E_{n}+\int_{s}^{t} R(\tau, s) d \tau
$$

The general solution to $(2.1)$ is of the form

$$
x(t)=X(t) \alpha+\int_{0}^{t} C_{1}(t, s) f(s) d s
$$

with arbitrary $\alpha \in R^{n+m n}$.

As for (2.2), the following analogs of the above given relationships take place: the fundamental matrix $Z\left(t_{i}\right), i=0, \ldots, \mu$, to the homogeneous equation (2.2)

$$
z\left(t_{i}\right)=\sum_{j=0}^{i-1} B_{i j}^{2} z\left(t_{j}\right), \quad i=1,2, \ldots, \mu,
$$

is the solution of the initial problem

$$
Z\left(t_{i}\right)=\sum_{j=0}^{i-1} B_{i j}^{2} Z\left(t_{j}\right), \quad i=1,2, \ldots, \mu, \quad Z\left(t_{0}\right)=E_{\nu} .
$$

The Cauchy matrix $C_{2}(i, j)$ is defined by

$$
C_{2}(i, j)=E_{\nu}+\sum_{k=j}^{i-1} B_{i k}^{2} C_{2}(k, j), \quad 1 \leqslant j \leqslant i \leqslant \mu,
$$

and gives the representation of the solution to (2.2) with the initial condition $z\left(t_{0}\right)=0$,

$$
z\left(t_{i}\right)=\left(C_{2} g\right)\left(t_{i}\right)=\sum_{j=1}^{i} C_{2}(i, j) g\left(t_{j}\right), \quad i=0,1, \ldots, \mu .
$$

In the sequel we put $C_{2}(i, j)=0$, if $j>i$.

Thus the general solution of $(2.2)$ has the representation

$$
z\left(t_{i}\right)=Z\left(t_{i}\right) \beta+\left(C_{2} g\right)\left(t_{i}\right), \quad i=0,1, \ldots, \mu,
$$

with arbitrary $\beta \in R^{\nu}$.

Now consider the homogeneous equation

$$
\dot{x}=\left[\mathcal{T}_{11}+\mathcal{T}_{12} C_{2} \mathcal{T}_{21}\right] x .
$$

The principal part of the operator $\mathcal{T}=\mathcal{T}_{11}+\mathcal{T}_{12} C_{2} \mathcal{T}_{21}$ is integral and Volterra with the kernel $\widetilde{K}(t, s)=K^{1}(t, s)+K^{2}(t, s)$ (see below (2.10), (2.11)). It is easy to see that this kernel satisfies the condition $\mathcal{K}$. Recall that the Cauchy matrix of (2.7) is completely defined by the kernel $\widetilde{K}(t, s)$.

Denote the fundamental matrix of (2.7) by $\widetilde{X}$, and let $\widetilde{C}_{1}$ be the Cauchy operator of this equation. 
MATHEMATICS

2019. Vol. 29. Issue 1

Theorem 1. The general solution of the continuous-discrete system (1.1) has the representation

$$
\left(\begin{array}{c}
x \\
z
\end{array}\right)=\mathcal{X}\left(\begin{array}{c}
\alpha \\
\beta
\end{array}\right)+\mathcal{C}\left(\begin{array}{l}
f \\
g
\end{array}\right)
$$

where the fundamental matrix $\mathcal{X}$ and the Cauchy operator $\mathcal{C}$ are defined by the equalities

$$
\mathcal{X}=\left(\begin{array}{ll}
\mathcal{X}_{11} & \mathcal{X}_{12} \\
\mathcal{X}_{21} & \mathcal{X}_{22}
\end{array}\right)
$$

and

$$
\mathcal{C}=\left(\begin{array}{ll}
\mathcal{C}_{11} & \mathcal{C}_{12} \\
\mathcal{C}_{21} & \mathcal{C}_{22}
\end{array}\right)
$$

Here the operator components $\mathcal{X}_{i j}$ and $\mathcal{C}_{i j}, i, j=1,2$, are defined by the equalities

$$
\begin{array}{rlrlrl}
\mathcal{X}_{11} & =\widetilde{X}, & \mathcal{X}_{12} & =\widetilde{C}_{1} \mathcal{T}_{12} Z, & \mathcal{X}_{21}=C_{2} \mathcal{T}_{21} \widetilde{X}, & \mathcal{X}_{22}=Z+C_{2} \mathcal{T}_{21} \widetilde{C}_{1} \mathcal{T}_{12} Z, \\
\mathcal{C}_{11}=\widetilde{C}_{1}, & \mathcal{C}_{12}=\widetilde{C}_{1} \mathcal{T}_{12} C_{2}, & \mathcal{C}_{21}=C_{2} \mathcal{T}_{21} \widetilde{C}_{1}, & \mathcal{C}_{22}=C_{2}+C_{2} \mathcal{T}_{21} \widetilde{C}_{1} \mathcal{T}_{12} C_{2} .
\end{array}
$$

$\mathrm{P} \mathrm{r}$ o o f. Let us apply the representation (2.6) to the second equation of (1.1):

$$
z=Z \beta+C_{2} \mathcal{T}_{21} x+C_{2} g .
$$

Substituting the right-hand side of the latter equality for $z$ on the right-hand side of (1.1) we obtain

$$
\dot{x}=\mathcal{T}_{11} x+\mathcal{T}_{12} Z \beta+\mathcal{T}_{12} C_{2} \mathcal{T}_{21} x+\mathcal{T}_{12} C_{2} g+f,
$$

or, changing the order of terms,

$$
\dot{x}=\mathcal{T}_{11} x+\mathcal{T}_{12} C_{2} \mathcal{T}_{21} x+\mathcal{T}_{12} Z \beta+\mathcal{T}_{12} C_{2} g+f .
$$

In what follows we will use the representation of the operator $\mathcal{T}_{12} C_{2} \mathcal{T}_{21}$. This one is obtained after calculating successively all values for arbitrary $x \in D S^{n}(m)$ :

$$
\begin{gathered}
\left(\mathcal{T}_{12} C_{2} \mathcal{T}_{21} x\right)(t)=\sum_{j: t_{j}<t} B_{j}^{1}(t) \sum_{l=1}^{j} C_{2}(j, l) \int_{0}^{t_{l}} K_{l}^{2}(s) \dot{x}(s) d s+ \\
+\sum_{j: t_{j}<t} B_{j}^{1}(t) \sum_{l=1}^{j} C_{2}(j, l) A_{l 0}^{0} x(0)+ \\
+\sum_{j: t_{j}<t} B_{j}^{1}(t) \sum_{l=1}^{j} C_{2}(j, l) \sum_{k=1}^{m} A_{l k}^{1} \Delta x\left(\tau_{k}\right) \chi_{\left[\tau_{k}, T\right]}\left(t_{l}\right) .
\end{gathered}
$$

Let us write the first term on the right-hand side of the latter equality in the form

$$
\int_{0}^{t} K^{2}(t, s) \dot{x}(s) d s
$$

where the kernel

$$
K^{2}(t, s)=\sum_{j: t_{j}<t} \sum_{l=1}^{j} B_{j}(t) \chi_{\left[0, t_{l}\right]}(s) C_{2}(j, l) K_{l}^{2}(s)
$$

satisfies the condition $\mathcal{K}$. It follows from (2.5) that $x=\widetilde{X} \alpha+\widetilde{C}_{1} \mathcal{T}_{12} Z \beta+\widetilde{C}_{1} \mathcal{T}_{12} C_{2} g+\widetilde{C}_{1} f$. Thus, turning back to $z$, we have

$$
z=Z \beta+C_{2} \mathcal{T}_{21}\left[\tilde{X} \alpha+\widetilde{C}_{1} \mathcal{T}_{12} Z \beta+\widetilde{C}_{1} \mathcal{T}_{12} C_{2} g+\widetilde{C}_{1} f\right]+C_{2} g
$$

or

$$
z=\left[C_{2} \mathcal{T}_{21} \tilde{X}\right] \alpha+\left[Z+C_{2} \mathcal{T}_{21} \widetilde{C}_{1} \mathcal{T}_{12} Z\right] \beta+\left[C_{2}+C_{2} \mathcal{T}_{21} \widetilde{C}_{1} \mathcal{T}_{12} C_{2}\right] g+C_{2} \mathcal{T}_{21} \widetilde{C}_{1} f
$$

Now with the use of (2.8) and (2.9) we obtain the statement of the theorem. 


\section{$\S 3$. The representation of the Cauchy matrix components}

As is shown in $[6$, p. $68 ; 8$, p. 57], the properties we study here are of considerable importance in different questions of the theory of functional differential equations. In particular, the smoothness of the Cauchy matrix in the first argument answers the question of differentiability under the integral in the integral representation for the components with continuous time, the properties of the Cauchy matrix as a function of the second argument impact onto conditions of the continuous dependence of solutions on the initial point in time and the true smoothness of the control function under the study of various classes of control problems. To study the above-mentioned properties, we derive here an explicit representation for the components of the Cauchy operator to the continuous-discrete system in the terms of matrices $\widetilde{C}_{1}$ and $C_{2}$.

1. The representation of $\mathcal{C}_{11}=\widetilde{C}_{1}$,

$$
\left(\mathcal{C}_{11} f\right)(t)=\int_{0}^{t} \widetilde{C}_{1}(t, s) d s
$$

does not need any discussion since all properties of $\widetilde{C}_{1}(t, s)$ are defined by the properties of the kernel $K(t, s)$. Some of them are described below.

2. The representation of the operator $\mathcal{C}_{12}=\widetilde{C}_{1} \mathcal{T}_{12} C_{2}$. By definition we have

$$
\left(\mathcal{C}_{12} g\right)(t)=\int_{0}^{t} \widetilde{C}_{1}(t, s) \sum_{j: t_{j} \leqslant s} B_{j}^{1}(s) \sum_{l=1}^{j} C_{2}(j, l) g\left(t_{l}\right) d s .
$$

With the use of the characteristic function $\chi_{\left(t_{j}, T\right]}(s)$ we rewrite the latter expression in the form

$$
\left(\mathcal{C}_{12} g\right)(t)=\int_{0}^{t} \widetilde{C}_{1}(t, s) \sum_{j=1}^{\mu} B_{j}^{1}(s) \chi_{\left(t_{j}, T\right]}(s) \sum_{l=1}^{j} C_{2}(j, l) g\left(t_{l}\right) d s,
$$

which is more convenient for the foregoing change of summation order. Once the order has been changed, we obtain

$$
\left(\mathcal{C}_{12} g\right)(t)=\int_{0}^{t} \widetilde{C}_{1}(t, s) \sum_{l=1}^{\mu} \sum_{j=l}^{\mu} B_{j}^{1}(s) \chi_{\left(t_{j}, T\right]}(s) C_{2}(j, l) g\left(t_{l}\right) d s .
$$

This gives

$$
\left(\mathcal{C}_{12} g\right)(t)=\sum_{l=1}^{\mu} \int_{0}^{t} \widetilde{C}_{1}(t, s) \mathcal{F}_{l}(s) d s g\left(t_{l}\right)
$$

where

$$
\mathcal{F}_{l}(s)=\sum_{j=l}^{\mu} B_{j}^{1}(s) \chi_{\left(t_{j}, T\right]}(s) C_{2}(j, l)
$$

3. The representation of the operator $\mathcal{C}_{21}=C_{2} \mathcal{T}_{21} \widetilde{C}_{1}$. First we calculate $\left(\mathcal{T}_{21} \widetilde{C}_{1} f\right)\left(t_{i}\right)$ for an arbitrary element $f \in L^{n}$ :

$$
\begin{gathered}
\left(\mathcal{T}_{21} \widetilde{C}_{1} f\right)\left(t_{i}\right)=\int_{0}^{t_{i}} K_{i}^{2}(s) \int_{0}^{s} \frac{\partial}{\partial s} \widetilde{C}_{1}(s, \tau) f(\tau) d \tau d s+\int_{0}^{t_{i}} K_{i}^{2}(s) f(s) d s= \\
=\int_{0}^{t_{i}} \int_{\tau}^{t_{i}} K_{i}^{2}(s) \frac{\partial}{\partial s} \widetilde{C}_{1}(s, \tau) d s f(\tau) d \tau+\int_{0}^{t_{i}} K_{i}^{2}(s) f(s) d s=
\end{gathered}
$$


MATHEMATICS

2019. Vol. 29. Issue 1

$$
=\int_{0}^{t_{i}} \int_{s}^{t_{i}} K_{i}^{2}(\tau) \frac{\partial}{\partial \tau} \widetilde{C}_{1}(\tau, s) d \tau f(s) d s+\int_{0}^{t_{i}} K_{i}^{2}(s) f(s) d s=\int_{0}^{t_{i}} \vartheta_{i}(s) f(s) d s,
$$

where

$$
\vartheta_{i}(s)=K_{i}^{2}(s)+\int_{s}^{t_{i}} K_{i}^{2}(\tau) \frac{\partial}{\partial \tau} \widetilde{C}_{1}(\tau, s) d \tau
$$

It should be noted that the second and the third terms of $\mathcal{T}_{21}$ do not take part in the representation obtained since any image of $\widetilde{C}_{1}$ takes zero initial value and zero jumps $\Delta_{k}$. Finally, we get

$$
\left(\mathcal{C}_{21} f\right)\left(t_{i}\right)=\sum_{j=1}^{i} C_{2}(i, j) \int_{0}^{t_{j}} \vartheta_{j}(s) f(s) d s .
$$

4. The representation of the operator $\mathcal{C}_{22}=C_{2}+C_{2} \mathcal{T}_{21} \widetilde{C}_{1} \mathcal{T}_{12} C_{2}$. Let us use the representation of $\mathcal{T}_{12} C_{2}$ :

$$
\left(\mathcal{T}_{12} C_{2} g\right)(t)=\sum_{l=1}^{\mu} \sum_{j=l}^{\mu} B_{j}^{1}(t) \chi_{\left(t_{j}, T\right]}(t) C_{2}(j, l) g\left(t_{l}\right)=\sum_{l=1}^{\mu} \mathcal{F}_{l}(t) g\left(t_{l}\right)
$$

(see (3.3)).

From this it follows that:

$$
\left(\mathcal{C}_{22} g\right)\left(t_{i}\right)=\sum_{j=1}^{i} C_{2}(i, j) g\left(t_{l}\right)+\sum_{j=1}^{i} C_{2}(i, j) \int_{0}^{t_{j}} \vartheta_{j}(s) \sum_{l=1}^{\mu} \mathcal{F}_{l}(s) g\left(t_{l}\right) d s .
$$

Taking into account $C_{2}(i, j)=0$, if $j>i$, we rewrite this in the form

$$
\left(\mathcal{C}_{22} g\right)\left(t_{i}\right)=\sum_{l=1}^{\mu}\left[C_{2}(i, l)+\sum_{j=1}^{i} C_{2}(i, j) \int_{0}^{t_{j}} \vartheta_{j}(s) \mathcal{F}_{l}(s) d s\right] g\left(t_{l}\right) .
$$

The representations (3.1), (3.2), (3.4), (3.5) of the Cauchy operator components for (1.1) make it possible to describe their properties, which are useful in the study of boundary value problems and control problems for continuous-discrete systems. In this case the components with continuous time $\widetilde{C}_{1}(t, s)$ and $\widetilde{C}_{1}(t, s) \mathcal{F}_{l}(s)$ are of principal interest. For the second term, the properties of the Cauchy matrix depend on the additional factor $\mathcal{F}_{l}(s)$ whose properties are derived from (3.2). That is why we dwell on the properties of $\widetilde{C}_{1}(t, s)$ in more detail. It should be noted that the absolutely continuity of this component follows immediately from its definition. It is noted before that the properties of $\widetilde{C}_{1}(t, s)$ as a function of the second argument are completely defined by the corresponding properties of the kernel

$$
\widetilde{K}(t, s)=K^{1}(t, s)+K^{2}(t, s),
$$

where $K^{1}(t, s)$ is the kernel of the principal part to the right-hand side of the subsystem with continuous time, and the kernel $K^{2}(t, s)$ is defined by (2.11). The theorems we give below are formulated in the terms of $\widetilde{K}(t, s)$, they are analogs to the theorems from [13, p. 58-64]. For all these theorems, in addition to the condition $\mathcal{K}$, the following condition $\mathcal{B} \mathcal{V}$ is assumed to be fulfilled:

for almost every $t \in[0, T]$, the elements $k_{i j}(t, s)$ of $\widetilde{K}(t, s)$ have bounded variation in $s$ on $[0, t]$, and

$$
\int_{0}^{T} \underset{s \in[0, \tau]}{\operatorname{Var}} k_{i j}(\tau, s) d \tau<\infty, \quad i, j=1,2, \ldots, n
$$

Before we establish some properties of $\widetilde{C}_{1}(t, s)$ as a function of the second argument, it should be noted that in the general case $\widetilde{C}_{1}(t, \cdot)$, being the kernel of an integral operator, is defined in a class of equivalent functions. So it can be changed on any set of zero measure with no impact on values 
of the integral operator. This is why in studying the properties of $\widetilde{C}_{1}(t, \cdot)$ such as the continuity we have to define this function definitely everywhere on $[0, t]$ having in mind the corresponding fixed representative of the above class. In the case of the condition $\mathcal{B V}$, we define this representative by (2.3) or (2.4) for each $s \in[0, t]$.

Theorem 2. For any $t \in[0, T]$, the matrix $\widetilde{C}_{1}(t, s)$ has bounded variation in $s$ on $[0, t]$.

P r o o f. In [16, p. 40-44] it is shown that, for a kernel $\widetilde{K}(t, s)$ with the condition $\mathcal{K}$, its resolvent kernel $\widetilde{R}(t, s)$ satisfies this condition too with another majorant $\widetilde{\kappa}(t)=d \kappa(t)$, where the constant $d$ can be calculated. Taking into account this and (2.4), we can find a nonnegative matrix $M$ such that the inequality $\left|\widetilde{C}_{1}(t, s)\right| \leqslant M$ holds. Here and in the sequel, for a matrix $A=\left\{a_{i j}\right\}$, $\lfloor A\rfloor$ stands for $\left\{\left|a_{i j}\right|\right\}$. For any partition $0 \leqslant s_{1} \leqslant \cdots \leqslant s_{m} \leqslant t$ we have

$$
\sum_{i}\left\lfloor\widetilde{C}_{1}\left(t, s_{i+1}\right)-\widetilde{C}_{1}\left(t, s_{i}\right)\right\rfloor \leqslant M \int_{0}^{T} \sum_{i}\left\lfloor\widetilde{K}\left(\tau, s_{i+1}\right)-\widetilde{K}\left(\tau, s_{i+1}\right)\right\rfloor d \tau
$$

which gives the statement of the theorem.

Theorem 3. Let $t \in(0, T]$ and $s_{0} \in[0, t]$. Then $\widetilde{C}_{1}(t, s)$ is continuous in $s$ at a point $s_{0}$, if for almost all $\tau \in\left[s_{0}, t\right]$ the function $\widetilde{K}(\tau, s)$ is continuous in $s$ at the point $s_{0}$.

P r o o f. Consider the difference $\widetilde{C}_{1}\left(t, s_{0}\right)-\widetilde{C}_{1}(t, s)$. By (2.3) we have

$$
\widetilde{C}_{1}\left(t, s_{0}\right)-\widetilde{C}_{1}(t, s)=\int_{s_{0}}^{t} \widetilde{C}_{1}(t, \tau)\left[\widetilde{K}\left(\tau, s_{0}\right)-\widetilde{K}(\tau, s)\right] d \tau-\int_{s}^{s_{0}} \widetilde{C}_{1}(t, \tau) \widetilde{K}(\tau, s) d \tau .
$$

Let us estimate the left-hand side of the latter:

$$
\begin{aligned}
\left\lfloor\widetilde{C}_{1}\left(t, s_{0}\right)-\widetilde{C}_{1}(t, s)\right\rfloor \leqslant \int_{s_{0}}^{t}\left\lfloor\widetilde{C}_{1}(t, \tau)\right\rfloor\left\lfloor\widetilde{K}\left(\tau, s_{0}\right)-\widetilde{K}(\tau, s)\right\rfloor d \tau+ & \\
& +\left\lfloor\int_{s}^{s_{0}}\left\lfloor\widetilde{C}_{1}(t, \tau)\right\rfloor\lfloor\widetilde{K}(\tau, s)\rfloor d \tau\right\rfloor .
\end{aligned}
$$

Under the conditions of the theorem with the use of the estimate $\left\lfloor\widetilde{C}_{1}(t, s)\right\rfloor \leqslant M$ we can apply the Lebesgue theorem to the right-hand side of the latter as $s \rightarrow s_{0}$, which completes the proof.

Theorem 4. Assume $t_{1} \in(0, T]$ and $s_{0} \in[0, \tau]$. For any fixed $t \in\left[s, t_{1}\right]$, the function $\widetilde{C}_{1}(t, \cdot)$ is continuous at the point $s_{0}$ if and only if $\widetilde{K}(t, \cdot)$ is continuous at the point $s_{0}$ for almost all $t \in\left(s_{0}, t_{1}\right]$.

P r o o f. For definiteness we consider the case of continuity from the left.

We start with the necessity. Let us use $(2.3)$ as applied to $\widetilde{C}_{1}(t, s)$ with $\widetilde{K}(t, s)$ having bounded variation in $s$ for any fixed $t$. For each $t \in\left[s_{0}, T\right]$ there exists $\lim _{s \rightarrow s_{0}-0} \widetilde{K}(t, s)=\widetilde{K}\left(t, s_{0}-0\right)$. This gives the following equality:

$$
\lim _{s \rightarrow s_{0}-0} \int_{s}^{t} \widetilde{C}_{1}(t, \tau) \widetilde{K}(\tau, s) d \tau=\lim _{s \rightarrow s_{0}-0} \int_{s}^{s_{0}} \widetilde{C}_{1}(t, \tau) \widetilde{K}(\tau, s) d \tau+\lim _{s \rightarrow s_{0}-0} \int_{s_{0}}^{t} \widetilde{C}_{1}(t, \tau) \widetilde{K}(\tau, s) d \tau .
$$

The first term equals zero as the integral is absolutely continuous in the limits. As for the second, we have

$$
\int_{s_{0}}^{t} \widetilde{C}_{1}(t, \tau) \widetilde{K}\left(\tau, s_{0}-0\right) d \tau
$$

Thus we arrived at

$$
\widetilde{C}_{1}\left(t, s_{0}-0\right)=\int_{s_{0}}^{t} \widetilde{C}_{1}(t, \tau) \widetilde{K}\left(\tau, s_{0}-0\right) d \tau+E_{n}, \quad t \in\left[s_{0}, T\right],
$$


and

$$
\widetilde{C}_{1}\left(t, s_{0}\right)-\widetilde{C}_{1}\left(t, s_{0}-0\right)=\int_{s_{0}}^{t} \widetilde{C}_{1}(t, \tau)\left[\widetilde{K}\left(\tau, s_{0}\right)-\widetilde{K}\left(\tau, s_{0}-0\right)\right] d \tau, \quad t \in\left[s_{0}, T\right] .
$$

Therefore, under the conditions of the theorem we obtain

$$
\int_{s_{0}}^{t} \widetilde{C}_{1}(t, \tau)\left[\widetilde{K}\left(\tau, s_{0}\right)-\widetilde{K}\left(\tau, s_{0}-0\right)\right] d \tau=0, \quad t \in\left[s_{0}, t_{1}\right]
$$

Recall that the Cauchy matrix possesses the property that the equality

$$
\int_{s_{0}}^{t} \widetilde{C}_{1}(t, \tau) f(\tau) d \tau=0, \quad t \in\left[s_{0}, t_{1}\right]
$$

implies $f(t)=0$ for almost all $t \in\left[s_{0}, t_{1}\right]$ which completes the proof of the necessity.

As for the sufficiency, it can be proved in the same way as in the proof of Theorem 3.

Funding. The research was supported by the Russian Foundation for Basic Research (project no. 18-01-00332).

\section{REFERENCES}

1. Agranovich G. Some problems of discrete/continuous systems stabilization, Funct. Differ. Equ., 2003, vol. 10, no. 1-2, pp. 5-17. https://zbmath.org/?q=an:1175.93185

2. Agranovich G. Observability criteria of linear discrete-continuous system, Funct. Differ. Equ., 2009, vol. 16, no. 1, pp. 35-51. https://zbmath.org/?q=an:1172.93010

3. Andrianov D.L. Boundary value problems and control problems for linear difference systems with aftereffect, Russian Mathematics, 1993, vol. 37, no. 5, pp. 1-12.

https://zbmath.org/?q=an:0836.34087

4. Anokhin A.V. On linear impulse systems for functional differential equations, Soviet. Math. Dokl., 1986, vol. 33, pp. 220-223. https://zbmath.org/?q=an:0615.34064

5. Ashordia M., Chania M., Kucia M. On the solvability of the periodic problem for systems of linear generalized ordinary differential equations, Mem. Differ. Equ. Math. Phys., 2018, vol. 74, pp. 7-26. https: / zbmath.org/?q=an:1398.34036

6. Azbelev N.V., Maksimov V.P., Rakhmatullina L.F. Vvedenie v teoriyu funktsional'no-differentsial'nykh uravnenii (Introduction to the theory of functional differential equations), Moscow: Nauka, 1991.

7. Azbelev N.V., Maksimov V.P., Rakhmatullina L.F. Elementy sovremennoi teorii funktsional'nodifferentsial'nykh uravnenii. Metody i prilozheniya (Elements of the contemporary theory of functional differential equations. Methods and applications), Moscow-Izhevsk: Institute of Computer Science, 2002.

8. Azbelev N.V., Maksimov V.P., Rakhmatullina L.F. Introduction to the theory of functional differential equations: methods and applications, New York-Cairo: Hindawi Publishing Corporation, 2007.

9. Azbelev N.V., Maksimov V.P., Simonov P.M. Theory of functional differential equations and applications, International Journal of Pure and Applied Mathematics, 2011, vol. 69, no. 2, pp. 203-235. https: / /zbmath.org/?q=an: 1228.34001

10. Chadov A.L., Maksimov V.P. Linear boundary value problems and control problems for a class of functional differential equations with continuous and discrete times, Funct. Differ. Equ., 2012, vol. 19, no. 1-2, pp. 49-62. https://zbmath.org/?q=an:1322.34077

11. Kurzweil Ja. Generalized ordinary differential equations and continuous dependence on a parameter, Czechoslovak Mathematical Journal, 1957, vol. 7, pp. 418-449.

https://zbmath.org/?q=an:0090.30002

12. Maksimov V.P. The Cauchy formula for a functional differential equation, Differ. Uravn., 1977, vol. 13, no. 4, pp. 601-606 (in Russian). http://mi.mathnet.ru/eng/de3033

13. Maksimov V.P. Voprosy obshchei teorii funktsional'no-differentsial'nykh uravnenii (Problems of the general theory of functional differential equations), Perm: Perm State University, 2003.

14. Maksimov V.P. Theory of functional differential equations and some problems in economic dynamics, Proceedings of Conference on Differential and Difference Equations and Applications, New York-Cairo: Hindawi Publishing Corporation, 2006, pp. 757-765. 
15. Maksimov V.P. Some questions of the control theory for functional differential systems, Izvestiya Instituta Matematiki i Informatiki Udmurtskogo Gosudarstvennogo Universiteta, 2015, issue 2 (46), pp. 112-119 (in Russian). http://mi.mathnet.ru/eng/iimi310

16. Maksimov V.P. Continuous mathematical models, Perm: Perm State University, 2015.

17. Maksimov V.P. On a linear optimal control problem for linear functional differential systems with continuous and discrete times, Functional Differential Equations: Theory and Applications: Proceedings of Conference Dedicated to the 95th Birthday Anniversary of Professor N.V. Azbelev, Perm National Research Polytechnic University, Perm, 2018, pp. 134-141 (in Russian). https: / /elibrary.ru/item.asp?id=35107826

18. Maksimov V.P. On a class of optimal control problems for functional differential systems, Tr. Inst. Mat. Mekh. Ural. Otd. Ross. Akad. Nauk, 2018, vol. 24, no. 1, pp. 131-142 (in Russian).

https://doi.org/10.21538/0134-4889-2018-24-1-131-142

19. Maksimov V.P. Reliable computing experiment in the study of functional-differential equations: theory and applications, Journal of Mathematical Sciences, 2018, vol. 230, issue 5, pp. 712-716. https://doi.org/10.1007/s10958-018-3775-3

20. Maksimov V.P. Attainable values of on-target functionals for a functional differential system with impulses, Vestn. Tambov. Univ. Ser. Estestv. Tekh. Nauki, 2018, vol. 23, no. 123, pp. 441-447 (in Russian). https://doi.org/10.20310/1810-0198-2018-23-123-441-447

21. Maksimov V.P., Chadov A.L. Hybrid models in problems of economic dynamics, Perm University Herald. Economy, 2011, no. 2, pp. 13-23 (in Russian).

https://elibrary.ru/item.asp?id=17328178

22. Maksimov V.P., Chadov A.L. A class of controls for a functional-differential continuous-discrete system, Russian Mathematics, 2012, vol. 56, issue 9, pp. 62-65. https://doi.org/10.3103/S1066369x12090083

23. Maksimov V.P., Rumyantsev A.N. Boundary value problems and problems of pulse control in economic dynamics. Constructive study, Russian Mathematics, 1993, vol. 37, no. 5, pp. 48-62. https: / / zbmath.org/?q=an:0835.90017

24. Marchenko V.M. Hybrid discrete-continuous systems with control: II. State space method, Differential Equations, 2015, vol. 51, no. 1, pp. 54-68. https://doi.org/10.1134/s0012266115010061

25. Marchenko V.M. Controllability and observability of hybrid discrete-continuous systems in the simplest function classes, Differential Equations, 2015, vol. 51, no. 11, pp. 1461-1475. https://doi.org/10.1134/s0012266115110075

26. Marchenko V.M. Modal control of hybrid differential-difference systems and associated delay systems of neutral type in scales of differential-difference controllers, Differential Equations, 2017, vol. 53, no. 11, pp. 1458-1474. https://doi.org/10.1134/S0012266117110088

27. Šchwabik S. Generalized ordinary differential equations, Singapore: World Scientific, 1992.

28. Šchwabik S., Tvrdý M., Veivoda O. Differential and integral equations. Boundary value problems and adjoints, Prague: Academia, 1979.

Received 01.02.2019

Maksimov Vladimir Petrovich, Doctor of Physics and Mathematics, Professor, Department of Information Systems and Mathematical Methods in Economics, Perm State National Research University, ul. Bukireva, 15, Perm, 614990, Russia.

E-mail:maksimov@econ.psu.ru

\section{В. П. Максимов \\ Структура оператора Коши линейной непрерывно-дискретной функционально-дифференциальной системы с последействием и свойства его компонент}

Цитата: Вестник Удмуртского университета. Математика. Механика. Компьютерные науки. 2019. Т. 29. Вып. 1. С. 40-51.

Ключевые слова: линейные системы с последействием, непрерывно-дискретные функционально-дифференциальные системы, представление решений, оператор Коши. 


\section{DOI: $10.20537 / \mathrm{vm} 190104$}

В статье рассматривается класс линейных систем функционально-дифференциальных уравнений с последействием, непрерывным и дискретным временем и импульсными воздействиями (импульсные гибридные ФДУ). В центре внимания находятся конструкции операторов, позволяющих дать полное описание всех траекторий гибридной системы, и в терминах этих операторов формулировать условия разрешимости задач управления с выбором управлений из различных классов, давать описание (оценки) множеств достижимости при наличии ограничений на управление, а также получать условия разрешимости общих линейных краевых задач. Дается детальное описание всех компонент оператора Коши, изучаются их свойства. Для компонент с непрерывным временем получены условия их непрерывности по второму аргументу, влияющие на возможность выбора класса управляющих воздействий. Упомянутые конструкции систематически используют результаты о матрицах Коши систем ФДУ с непрерывным временем и систем разностных уравнений с дискретным временем.

Финансирование. Работа выполнена при поддержке Российского фонда фундаментальных исследований (проект № 18-01-00332).

\section{СПИСОК ЛИТЕРАТУРЫ}

1. Agranovich G. Some problems of discrete/continuous systems stabilization // Funct. Differ. Equ. 2003. Vol. 10. No. 1-2. P. 5-17. https://zbmath.org/?q=an:1175.93185

2. Agranovich G. Observability criteria of linear discrete-continuous system // Funct. Differ. Equ. 2009. Vol. 16. No. 1. P. 35-51. https://zbmath.org/?q=an: 1172 . 93010

3. Андрианов Д.Л. Краевые задачи и задачи управления для линейных разностных систем с последействием // Известия вузов. Математика. 1993. № 5. С. 3-16. http://mi.mathnet.ru/ivm4406

4. Анохин А.В. О линейных импульсных системах для функционально-дифференциальных уравнений // Доклады АН СССР. 1986. Т. 286. № 5. С. 1037-1040.

5. Ashordia M., Chania M., Kucia M. On the solvability of the periodic problem for systems of linear generalized ordinary differential equations // Mem. Differ. Equ. Math. Phys. 2018. Vol. 74. P. 7-26. https : / / zbmath .org/ ?q=an: 1398.34036

6. Азбелев Н.В., Максимов В.П., Рахматуллина Л.Ф. Введение в теорию функционально-дифференциальных уравнений. М.: Наука, 1991.

7. Азбелев Н.В., Максимов В.П., Рахматуллина Л.Ф. Элементы современной теории функциональнодифференциальных уравнений. Методы и приложения. М.-Ижевск: Институт компьютерных исследований, 2002.

8. Azbelev N.V., Maksimov V.P., Rakhmatullina L.F. Introduction to the theory of functional differential equations: methods and applications. New York-Cairo: Hindawi Publishing Corporation, 2007.

9. Azbelev N.V., Maksimov V.P., Simonov P.M. Theory of functional differential equations and applications // International Journal of Pure and Applied Mathematics. 2011. Vol. 69. No. 2. P. 203-235. https://zbmath.org/ ?q=an: 1228.34001

10. Chadov A.L., Maksimov V.P. Linear boundary value problems and control problems for a class of functional differential equations with continuous and discrete times // Funct. Differ. Equ. 2012. Vol. 19. No. 1-2. P. 49-62. https://elibrary.ru/item.asp?id=22291874

11. Kurzweil Ja. Generalized ordinary differential equations and continuous dependence on a parameter // Czechoslovak Mathematical Journal. 1957. Vol. 7. P. 418-449. https://zbmath.org/?q=an:0090.30002

12. Максимов В.П. О формуле Коши для функционально-дифференциального уравнения // Дифференциальные уравнения. 1977. Т. 13. № 4. С. 601-606. http://mi .mathnet.ru/de3033

13. Максимов В.П. Вопросы общей теории функционально-дифференциальных уравнений. Пермь: Изд-во Пермского государственного университета, 2003.

14. Maksimov V.P. Theory of functional differential equations and some problems in economic dynamics // Proceedings of the Conference on Differential and Difference Equations and Applications. New YorkCairo: Hindawi Publishing Corporation. 2006. P. 757-765.

15. Максимов В.П. Некоторые вопросы теории управления функционально-дифференциальными системами // Известия Института математики и информатики Удмуртского государственного университета. 2015. Вып. 2 (46). С. 112-119. http://mi.mathnet.ru/iimi310

16. Maksimov V.P. Continuous mathematical models. Perm: Perm State University, 2015. 
17. Максимов В.П. О линейной задаче оптимального управления для линейных функционально-дифференциальных систем с непрерывным и дискретным временем // Функционально-дифференциальные уравнения: теория и приложения. Материалы конференции, посвященной 95-летию со дня рождения профессора Н.В. Азбелева (Пермь, 17-19 мая 2017). Пермь: ПНИПУ, 2018. С. 134-141.

https://elibrary.ru/item.asp?id=35107826

18. Максимов В.П. Об одном классе задач оптимального управления для функционально-дифференциальных систем // Труды института математики и механики УрО РАН. 2018. Т. 24. № 1. С. $131-142$. https: / /doi.org/10.21538/0134-4889-2018-24-1-131-142

19. Maksimov V.P. Reliable computing experiment in the study of functional-differential equations: theory and applications // Journal of Mathematical Sciences. 2018. Vol. 230. No. 5. P. 712-716.

https://doi.org/10.1007/s10958-018-3775-3

20. Максимов В.П. Достижимые значения целевых функционалов для функционально-дифференциальной системы с импульсным воздействием // Вестник Тамбовского университета. Сер. Естественные и технические науки. 2018. Т. 23. № 123. С. 441-447.

https: / /oi.org/10.20310/1810-0198-2018-23-123-441-447

21. Максимов В.П., Чадов А.Л. Гибридные модели в задачах экономической динамики // Вестник Пермского университета. Сер. Экономика. 2011. № 2. С. 13-23.

https://elibrary.ru/item.asp?id=17328178

22. Максимов В.П., Чадов А.Л. Об одном классе управлений для функционально-дифференциальной непрерывно-дискретной системы // Известия вузов. Математика. 2012. № 9. С. 72-76.

http: //mi.mathnet.ru/ivm8740

23. Максимов В.П., Румянцев А.Н. Краевые задачи и задачи импульсного управления в экономической динамике. Конструктивное исследование // Известия вузов. Математика. 1993. № 5. С. 56-71. http: //mi.mathnet.ru/ivm4 419

24. Марченко В.М. Гибридные дискретно-непрерывные системы с управлением. II. Метод пространства состояний // Дифференциальные уравнения. 2015. Т. 51. № 1. С. 55-69.

https://doi.org/10.1134/S0374064115010069

25. Марченко В.М. Управляемость и наблюдаемость гибридных дискретно-непрерывных систем в простейших классах функций // Дифференциальные уравнения. 2015. Т. 51. № 11. С. 1469-1481. https://doi.org/10.1134/S0374064115110072

26. Марченко В.М. Модальное управление гибридными дифференциально-разностными системами с запаздывающим аргументом нейтрального типа в шкалах дифференциально-разностных регуляторов // Дифференциальные уравнения. 2017. Т. 53. № 11. С. 1491-1506. https://doi.org/10.1134/s0374064117110085

27. Šchwabik S. Generalized ordinary differential equations. Singapore: World Scientific, 1992.

28. Šchwabik S., Tvrdý M., Veivoda O. Differential and integral equations. Boundary value problems and adjoints. Prague: Academia, 1979.

Поступила в редакцию 01.02 .2019

Максимов Владимир Петрович, д.ф.-м.н., профессор, кафедра информационных систем и математических методов в экономике, Пермский государственный национальный исследовательский университет, 614990, Россия, г. Пермь, ул. Букирева, 15.

E-mail:maksimov@econ.psu.ru 